\title{
Preparation and characterization of N-benzyl-N,O-succinyl chitosan polymeric micelles for solubilization of poorly soluble non-steroidal anti-inflammatory drugs
}

\author{
Thisirak Woraphatphadung ${ }^{1}$, Warayuth Sajomsang ${ }^{2}$, Theerasak Rojanarata', \\ Prasert Akkaramongkolporn ${ }^{1}$, Tanasait Ngawhirunpat $^{1}$ and Praneet \\ Opanasopit ${ }^{1 *}$ \\ ${ }^{1}$ Pharmaceutical Development of Green Innovations Group (PDGIG), Faculty of Pharmacy, Silpakorn University, Nakhon \\ Pathom, 73000, ${ }^{2}$ National Nanotechnology Center (NANOTEC), National Science and Technology Development Agency \\ (NSTDA), Thailand Science Park, Pathum Thani, 12120, Thailand
}

*For correspondence: Email: opanasopit_p@su.ac.th; Tel: 66-34-255800; Fax: 66-34-255801

Sent for review: 6 February 2017

Revised accepted: 5 September 2017

\begin{abstract}
Purpose: To investigate the solubilization of poorly water-soluble non-steroidal anti-inflammatory drugs (NSAIDs) in N-benzyl-N,O-succinyl chitosan (BSCS) polymeric micelles

Methods: BSCS was synthesized by reductive amination and succinylation, respectively. NSAIDs; meloxicam (MX), piroxicam (PRX), ketoprofen (KP) and indomethacin (IND) were entrapped in the hydrophobic inner cores by evaporation method. The effects of drug structure on loading efficiency, particle size and surface charge of micelles were investigated.

Results: The critical micelle concentration of BSCS micelles was $0.0385 \mathrm{mg} / \mathrm{mL}$ and cytotoxicity on Caco-2 cells depends on the polymer concentration $\left(I C_{50}=3.23 \pm 0.08 \mathrm{mg} / \mathrm{mL}\right)$. BSCS micelles were able to entrap MX, PRX, KP and IND and also improve the solubility of drugs. Drug loading efficiency was highly dependent on the drug molecules. The drug loading capacity of these BSCS micelles was in the following rank order: KP $(282.9 \mu \mathrm{g} / \mathrm{mg})>P R X(200.8 \mu \mathrm{g} / \mathrm{mg})>M X(73.7 \mu \mathrm{g} / \mathrm{mg})>I N D(41.2$ $\mu \mathrm{g} / \mathrm{mg}$ ). The highest loading efficiency was observed in KP-loaded BSCS micelles due to the attractive force between phenyl groups of KP and benzyl groups of the polymer. Particle size and surface charge were in the range of $312-433 \mathrm{~nm}$ and -38 to $-41 \mathrm{mV}$, respectively.

Conclusion: BSCS copolymer presents desirable attributes for enhancing the solubility of hydrophobic drugs. Moreover, BSCS polymeric micelles might be beneficial carrier in a drug delivery system.
\end{abstract}

Keywords: BSCS, polymeric micelles, solubilization, non-steroidal anti-inflammatory drugs

Tropical Journal of Pharmaceutical Research is indexed by Science Citation Index (SciSearch), Scopus, International Pharmaceutical Abstract, Chemical Abstracts, Embase, Index Copernicus, EBSCO, African Index Medicus, JournalSeek, Journal Citation Reports/Science Edition, Directory of Open Access Journals (DOAJ), African Journal Online, Bioline International, Open-J-Gate and Pharmacy Abstracts

\section{INTRODUCTION}

One-third of the drugs identified are poorly water soluble, which is one of the important hindrances for successful development and the therapy of the orally administered drug effective $[1,2]$. Based on the Biopharmaceutics Classification System (BCS), these drugs could be classified as class II and class IV. The rate and extent of absorption as well as the bioavailability of class II and IV drugs are ultimately depends on solubility of the drugs[3].The most commonly used techniques for increasing the drug solubility are solid dispersions, cosolvency, $\mathrm{pH}$ adjustment, micellization, etc [4].

The core-shell polymeric micelles is an alternative technique to dissolve hydrophobic 
drugs. Drug-incorporated polymeric micelles can be formulated from amphiphilic copolymer with entrapped drug in the hydrophobic inner core and hydrophilic segment surrounding aqueous medium to stabilize the micelles. There has been great importance in the use of polymeric micelles as drug carriers [5]. The successful of hydrophobic drugs loaded into polymeric micelles can solubilize $10-5000$ fold in aqueous solutions [6].

Chitosan (CS) and its derivatives are currently receiving attention in medical and pharmaceutical applications because of biodegradable, biocompatible and less expensive $[7,8]$. Generally, CS dissolve in aqueous acidic media. However, it cannot formulate polymeric micelles in water. CS derivatives have been modified in order to improve the solubility and employed in various formulations for the delivery of hydrophobic drugs such as microspheres, nanoparticles [9-11]. In our previous work, $\mathrm{pH}$ sensitive polymers from chitosan-based were successfully synthesized, and applied in oral curcumin [12] and oral meloxicam (MX) deliveries [13]. The evaporation method presented higher MX incorporated into NSCS polymeric micelles than other entrapment methods. In addition, the cytotoxicity of BSCS micelles had low on Caco-2 cells [14]. Therefore, in this experiment, BSCS was synthesized and used to entrap four NSAIDs with poorly water solubility, including $M X$, piroxicam (PRX), ketoprofen (KP) and indomethacin (IND) as model drugs in the hydrophobic core of the polymeric micelles by evaporation method to investigate the effect of drug structure on the loading efficiency and solubility improvement.

\section{EXPERIMENTAL}

\section{Materials}

Chitosan (CS) (DDA $=96 \pm 2 \%$ as investigated using NMR) was obtained from OilZac Technologies (Bangkok, Thailand) [12,13]. Benzaldehyde, sodium borohydride $\left(\mathrm{NaBH}_{4}\right)$, succinic anhydride, MX, PRX, KP and IND were procured from Sigma Aldrich (St. Louis, USA). Dialysis tube (MWCO $=3500 \mathrm{Da}$ ) was obtained from Cellu Sep T1 (Segiun, USA).The Caco-2 cell line was obtained from the American Type Culture Collection (Rockville, USA). All other substances were of analytical grade.

\section{Synthesis of amphiphilic derivatives of chitosan}

The modified chitosan derivative, $\mathrm{N}$-benzyl-N,O- succinyl chitosan (BSCS), was produced using reductive benzylation and succinylation, respectively, for grafting hydrophobic and hydrophilic functional groups onto the CS structure as described in the literature $[12,14]$. Firstly, Benzaldehyde (2.0 meq/GlcN) was added in dissolving CS solution. The mixture solution was then stirred for $24 \mathrm{~h}$ at room temperature, and adjusted $\mathrm{pH}$ to 5 by $1 \mathrm{M}$ sodium hydroxide. The reaction mixture was converted by sodium borohydride $(52.9 \mathrm{mmol})$ to obtain the $\mathrm{N}$-benzyl chitosan (BCS). Next step, BCS was dispersed in $\mathrm{N}, \mathrm{N}$-dimethylformamide (DMF). Succinic anhydride $(5.0 \mathrm{meq} / \mathrm{GlcN})$ was added in BCS solution via $\mathrm{N}, \mathrm{O}$-succinylation reaction under nitrogen atmosphere for $24 \mathrm{~h}$ at $100^{\circ} \mathrm{C}$. After cooling process, the reaction mixture was filtered and dialyzed against deionized water to obtain the clear solution. Finally, the obtained amphiphilic CS derivative was dried to collect by freeze dehydration.

\section{Characterization amphiphilic derivatives of chitosan}

The CS or BSCS sample was measured ${ }^{1} \mathrm{H}$ NMR spectrometer (Bruker, Switzerland). Tetramethylsilane (TMS) was exploited as an internal standard [13]. Fourier transform infrared (FTIR) was carried out using a Nicolet 6700 spectrometer (Thermo Company, USA) at $25^{\circ} \mathrm{C}$. The molecular weight of amphiphilic CS derivative was evaluated via gel permeation chromatography (GPC) analysis utilizing a waters $600 \mathrm{E}$ series instrument equipped with an ultrahydrogel column, and a water 2410 refractive index (RI) detector [12].

Fluorescence spectroscopy was used to investigate the critical micelle concentration (CMC) of BSCS using hydrophobic pyrene as a fluorescent probe [15]. An aliquot $(10 \mu \mathrm{L})$ of 1 $\mathrm{mM}$ pyrene solution in acetone was placed in the small glass bottles containing a concentration sequence of aqueous copolymer media from 0.5 $\times 10^{-3}$ to $3.9 \times 10^{-3} \mathrm{mg} / \mathrm{mL}(4 \mathrm{~mL})$. The amount was adjusted to give a pyrene concentration in the final solution of each sample at $2.5 \times 10^{-6} \mathrm{M}$. The mixture solutions were sonicated for $15 \mathrm{~min}$, heated at $50^{\circ} \mathrm{C}$ for $2 \mathrm{~h}$ to equilibrate the pyrene and the micelles, and then stored to cool overnight in dark at ambient temperature. Fluorescence excitation was set at $335 \mathrm{~nm}$, and the emission band was observed from 350 to 500 $\mathrm{nm}$. After measuring, the intensity ratio of $I_{373} / I_{382}$ was plotted as a function of logarithm the concentration of polymer and the CMC was calculated.

Trop J Pharm Res, October 2017; 16(10): 2350 


\section{In vitro cytotoxicity assay}

The in vitro cytotoxicity of blank BSCS against Caco-2 cells was investigated by an MTT assay [16]. Overall, The Caco-2 cells were incubated in DMEM solution at $\mathrm{pH} 7.4$ and were kept at $37^{\circ} \mathrm{C}$ in $5 \% \mathrm{CO}_{2}$ atmosphere. The cells were seeded into each well of 96-well plates with a density of 10,000 cells/well and pre-incubated for $24 \mathrm{~h}$ to allow cell attachment.

Thereafter, blank micelles in $100 \mu \mathrm{L}$ of DMEM were added to each well of the Caco-2 cells. After $24 \mathrm{~h}$, the medium was removed and the wells were washed. Then, the wells were filled with $200 \mu \mathrm{L}$ of new medium, and incubated the cells were with MTT solution $(1 \mathrm{mg} / \mathrm{mL})$ for additional $4 \mathrm{~h}$. After removal of the medium, 100 $\mu \mathrm{L}$ of DMSO was added to dissolve the formed formazan crystals. The cell viability was calculated based on the absorbance measurements at $550 \mathrm{~nm}$ using a microplate reader (Packard BioScience, USA). The viability of non-treated control cells was arbitrarily defined as $100 \%$.

\section{Preparation of drug-loaded polymeric micelles}

A mixed-solvent evaporation method was selected to prepare polymeric micelles as previously described [13]. Briefly, $5 \mathrm{mg}$ of BSCS and drugs (MX, PRX, KP, IND) (at $40 \%$ concentration of the drug to polymer) were dissolved in DMF in a small glass container. After dissolving, small amount of acetone was added and stirred at ambient temperature. The solvent of the mixed solution was then completely evaporated under nitrogen gas flow. Then, deionized water $(3 \mathrm{~mL})$ was added, and the mixture was sonicated for $20 \mathrm{~min}$ at $80{ }^{\circ} \mathrm{C}$ using a probe sonicator (model CV 244, USA). The micellar solution was then centrifuged at 1000 rpm for $2 \mathrm{~min}$, filtered through a $0.45-\mu \mathrm{m}$ membrane filter to remove insoluble drug.

\section{Determination of entrapment efficiency}

To measure drug loading efficiency and loading capacity, $0.1 \mathrm{~mL}$ of the drug-incorporated polymeric micelles were mixed with $0.9 \mathrm{~mL}$ of a mixture solvent of dimethyl sulfoxide (DMSO) : $\mathrm{H}_{2} \mathrm{O}(9: 1)$. The drug content incorporated into BSCS micelles was measured using HPLC (Agilent technologies, USA). The entrapment efficiency (EE) and loading capacity (LC) of the drugs were calculated according to Eqs.1 and 2, respectively. All samples were analyzed in triplicate.

$\mathrm{EE}(\%)=\left(\mathrm{C}_{1} / \mathrm{C}_{2}\right) 100$

where $C_{1}$ is the amount of drug loaded into the polymeric micelles, and $\mathrm{C}_{2}$ is the initial amount of drug used for preparation.

$\operatorname{LC}(\mu g / m g)=\left(I_{1} / L_{2}\right)$

where $L_{1}$ is the amount of drug incorporated into the polymeric micelles, and $L_{2}$ is the amount of BSCS used for the preparation.

\section{High performance liquid chromatography (HPLC) conditions}

The amount of the drugs encapsulated into the polymeric micelles was investigated using by HPLC with a Luna $^{\circledR} 5 \mu \mathrm{m}$ C18 (2) column according to a calibration curve generated from a series of standard solutions ranging from 5 to 50 $\mu \mathrm{g} / \mathrm{mL}$. The injection volume was $20 \mu \mathrm{L}$. The mobile phase used for each drug was described in Table 1 [17-19].

Table 1: HPLC experimental conditions used to quantify NSAIDs concentrations [17-19]

\begin{tabular}{|c|c|c|c|}
\hline Drug & Mobile phase & $\begin{array}{c}\text { Flow } \\
\text { rate } \\
\text { (mL/min) }\end{array}$ & $\begin{array}{l}\text { Wavelength } \\
(\mathrm{nm})\end{array}$ \\
\hline$M X$ & $\begin{array}{l}\text { Potassium } \\
\text { dihydrogen } \\
\text { phosphate }(\mathrm{pH} \\
\text { 4.4):MeOH:ACN } \\
(45: 45: 10, \mathrm{v} / \mathrm{v} / \mathrm{v})\end{array}$ & 1.0 & 365 \\
\hline PRX & $\begin{array}{l}\text { Water: } \\
\text { methanol } \\
(45: 55) \text { pH3.2 }\end{array}$ & 1.0 & 360 \\
\hline KP & $\begin{array}{l}0.2 \% \\
\text { phosphoric } \\
\text { acid:acetronitrile } \\
(50: 50)\end{array}$ & 1.2 & 255 \\
\hline IND & $\begin{array}{l}0.2 \% \\
\text { phosphoric } \\
\text { acid:acetronitrile } \\
(50: 50)\end{array}$ & 1.8 & 230 \\
\hline
\end{tabular}

Polymeric micelle size and surface charge measurement

The mean particle diameter and surface charge of the BSCS polymeric micelles with and without drugs were assessed using Zetasizer Nano ZS (Malvern, UK) in triplicate at $25^{\circ} \mathrm{C}$. The diluted micellar solution was passed through a $0.45-\mu \mathrm{m}$ membrane filter before measurement. 


\section{Statistical analysis}

All data are presented as mean \pm standard deviation (SD, $n=3)$. A one-way analysis of variance (ANOVA) was used to test the statistical significance between means using SPSS 17.0 statistical software program. A $p$-value of 0.05 or less was considered as statistically significant.

\section{RESULTS}

\section{Characteristics of BSCS}

Grafted copolymer, BSCS, was successfully synthesized onto a CS backbone via reductive benzylation and succinylation, respectively (Figure 1). Overall, the N-benzylation of CS occurred through the corresponding Schiff base intermediate, then the $\mathrm{N}, \mathrm{O}$-succinylation of BCS was performed by reacting with succinic anhydride in DMF at $100^{\circ} \mathrm{C}$.

BSCS was characterized using ${ }^{1} \mathrm{H}-\mathrm{NMR}$ spectroscopy, FTIR and GPC. The ${ }^{1} \mathrm{H}-\mathrm{NMR}$ spectrum of BSCS exhibited proton signal of the benzyl groups at $\delta 7.32 \mathrm{ppm}$ and the methylene protons of the succinyl moiety at $\delta 2.45 \mathrm{ppm}$, as shown in Figure 2 (a). FTIR spectrum of BCS, the result revealed that the features of additional absorption bands at 1600, 1494, 743 and 695 $\mathrm{cm}^{-1}$, compared with spectrum of CS. These bands were assigned to $\mathrm{C}=\mathrm{C}$ stretching and $\mathrm{C}-$
$\mathrm{H}$ deformation (out of plane), respectively, arising from the benzyl groups [20]. The BSCS spectrum exhibited a characteristic band at $1715 \mathrm{~cm}^{-1}$ that corresponds to $\mathrm{C}=\mathrm{O}$ stretching of the succinic acid moiety (Figure 2 (b)). The number average molecular weight $\left(M_{n}\right)$ of CS by GPC analysis was $7633 \mathrm{~g} / \mathrm{mol}$. After modification, the $M_{n}$ of BCS and BSCS was increased from 7633 to 10,552 and $15,628 \mathrm{~g} / \mathrm{mol}$, respectively. Moreover, the degree of substitution (DS) of copolymer was investigated using elemental analysis. The DS of the N-benzyl groups (DSB) and N,O-succinyl groups (DSS) was computed based on the $\mathrm{C} / \mathrm{N}$ molar ratio achieved from elemental analysis according to Eqs 3 and 4, respectively [14].

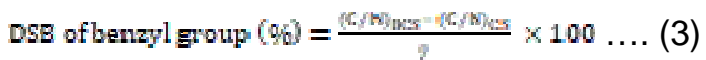

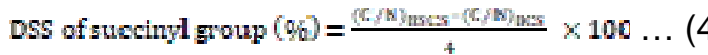

DSB was calculated to be 0.69 (approximately 32.4 repeating units) while the DSS was 1.08 (approximately 50.7 repeating units) $[12,14]$.

Self-assembly micelle formation of the BSCS copolymer occurs when the concentration is above the CMC, which determined by plotting the intensity ratio $I_{1} / l_{3}$ of pyrene versus concentration. The CMC value of BSCS was $0.0385 \mathrm{mg} / \mathrm{mL}$.

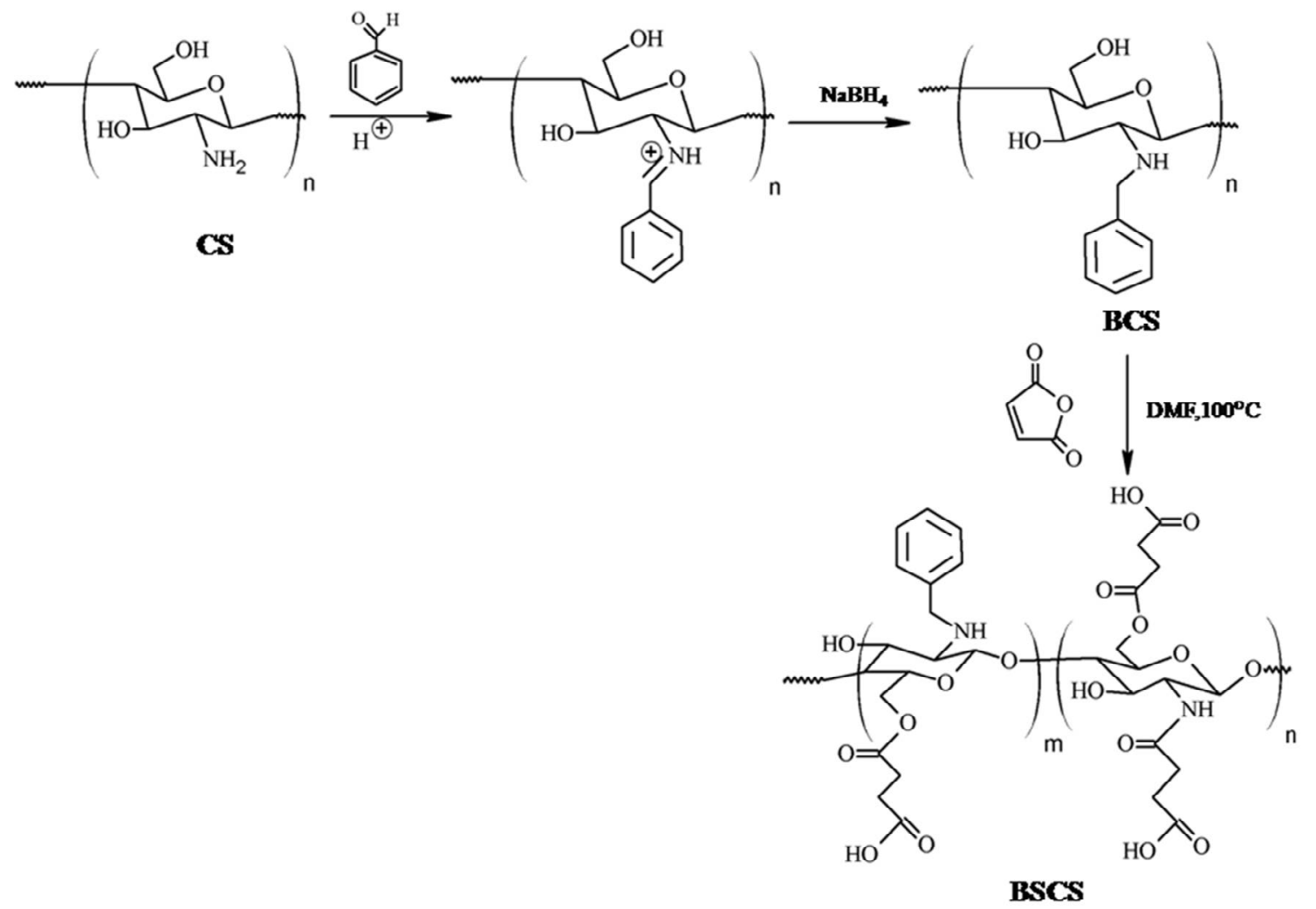

Figure 1: Schematic illustration of the synthesis of $\mathrm{N}$-benzyl- $N, \mathrm{O}$-succinyl chitosan (BSCS) graft copolymer 
a)

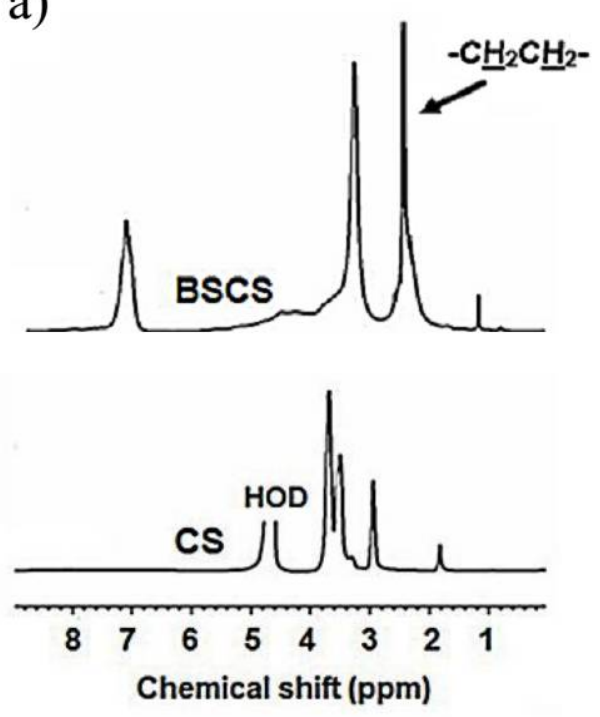

b)

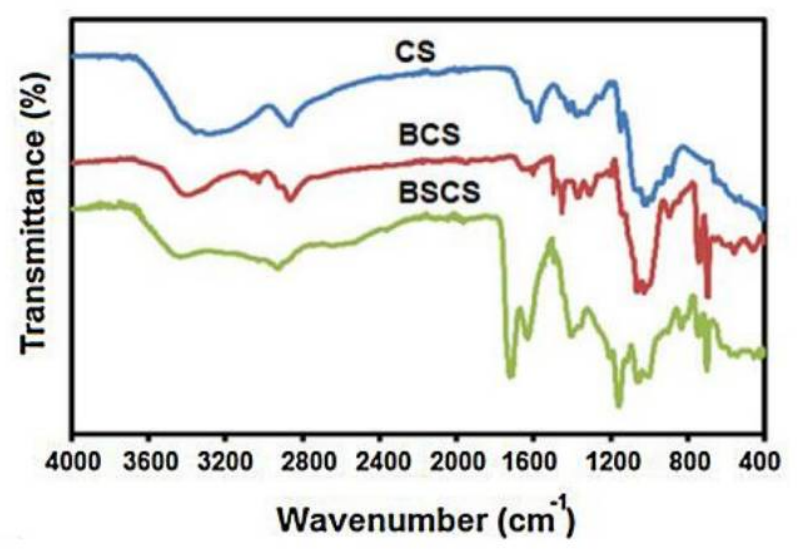

Figure 2: $1 \mathrm{H}$ NMR spectra of CS and BSCS (a) and ATR-FTIR of CS, BCS and BSCS (b)

\section{In vitro cytotoxicity}

The cytotoxicity of BSCS micelles was determined against Caco-2 cells. Figure 3 shows the viability of Caco-2 cells after treatment with various the concentration $(0.01-5 \mathrm{mg} / \mathrm{mL})$ of the modified polymer. The $\mathrm{IC}_{50}$ value was calculated to be $3.23 \pm 0.08 \mathrm{mg} / \mathrm{mL}$.

\section{Drug-loaded polymeric micelles}

In this study, four model NSAIDs drugs (MX, PRX, IND and KP) with poor aqueous solubility, presented the physicochemical properties in Table 2 [21,22], were selected to load into BSCS polymeric micelles. The EE (a) and LC (b) of all NSAIDs loaded into BSCS polymeric micelles are shown in Figure 4.

\section{Polymeric micelle size and surface charge}

The particle sizes, size distribution and surface charge of blank and four NSAIDs drugs loaded BSCS polymeric micelles are displayed in Table 3.



Figure 3: Cell viability in Caco-2 cells at varying concentrations of polymeric micelles $\left(n=5 ;{ }^{*} p<0.05\right)$ 
Table 2: Physicochemical properties of the drugs [21,22]

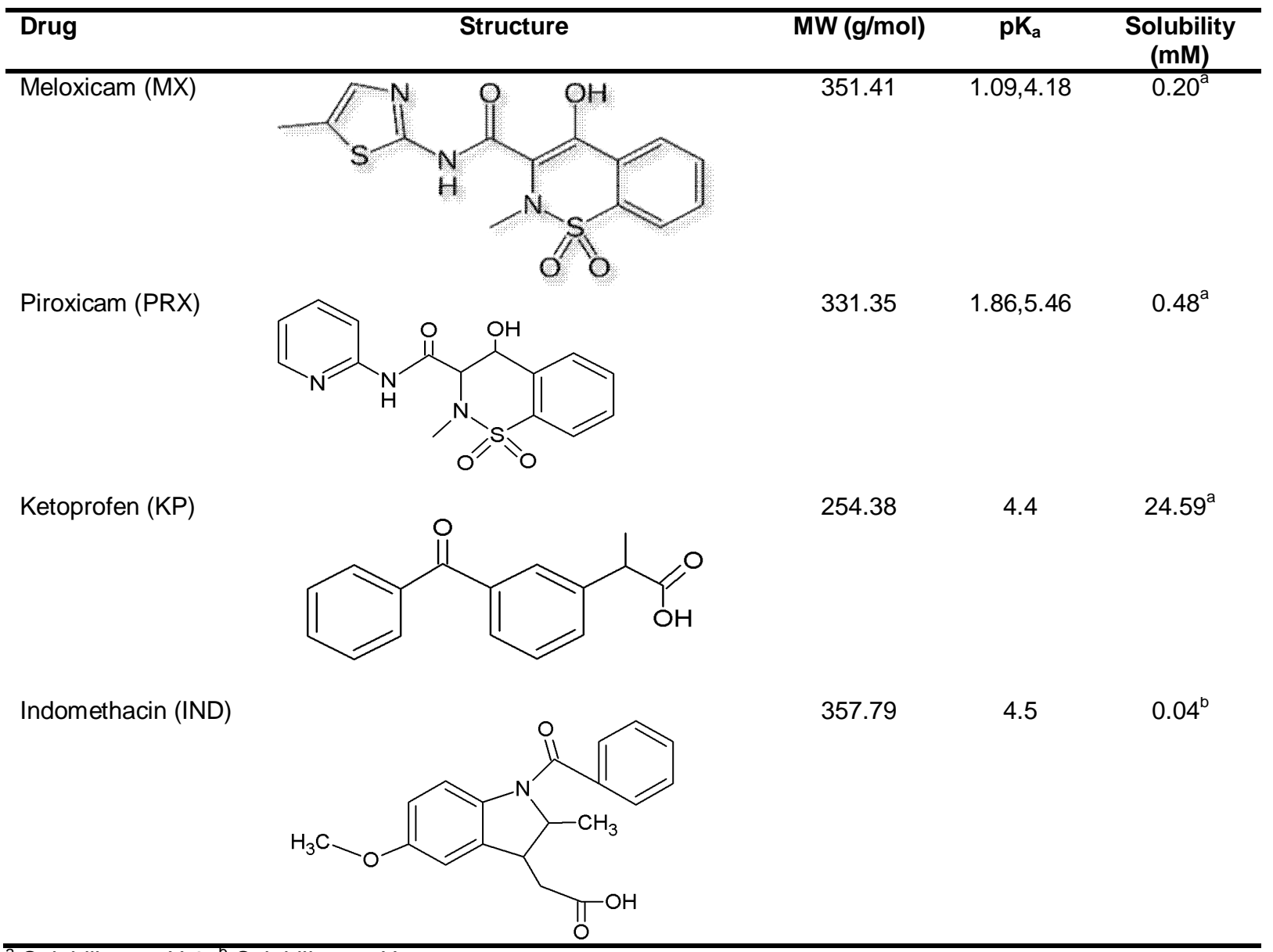

${ }^{a}$ Solubility at $\mathrm{pH} 6 ;{ }^{\circ}$ Solubility at $\mathrm{pH} 5.7$

a)

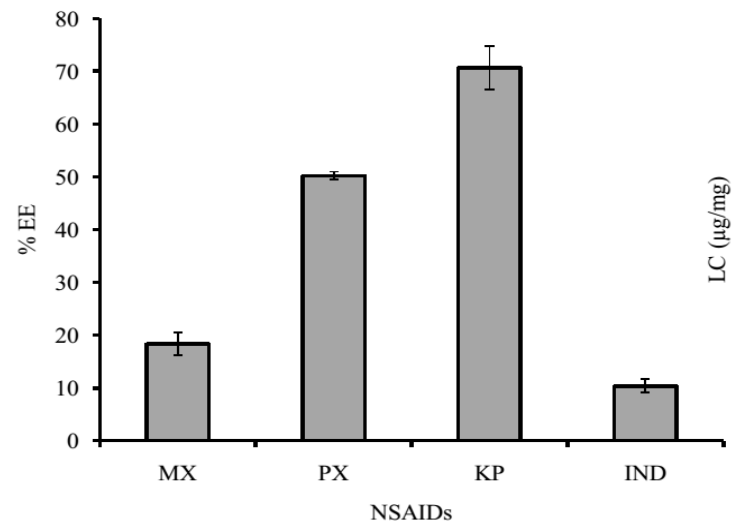

b)

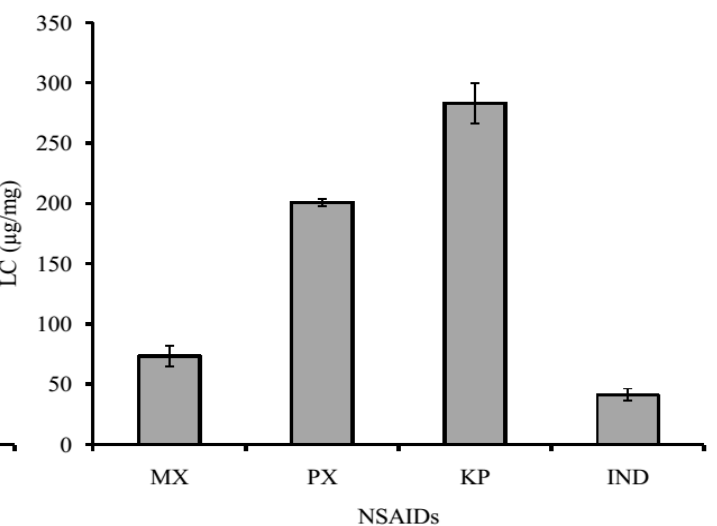

Figure 4: Entrapment efficiency (a) and loading capacity (b) of NSAIDs drugs (MX, PRX, KP and IND). Each value represents mean $\pm S D(n=3)$

Table 3: Particle size with polydispersity index (PDI) and surface charge of polymeric micelles with and without drugs. Each value represents mean $\pm \operatorname{SD}(n=3)$

\begin{tabular}{llll}
\hline Polymeric micelles (PMs) & Particle size $(\mathbf{n m})$ & PDI & Zeta potential $(\mathbf{m V})$ \\
\hline Blank-PMs & $226.63 \pm 9.57$ & 0.304 & $-39.60 \pm 1.91$ \\
MX -loaded PMs & $312.63 \pm 11.75$ & 0.386 & $-40.67 \pm 0.47$ \\
PRX-loaded PMs & $402.70 \pm 24.81$ & 0.420 & $-41.53 \pm 2.94$ \\
KP-loaded PMs & $349.23 \pm 7.89$ & 0.430 & $-38.13 \pm 1.92$ \\
IND-loaded PMs & $433.53 \pm 2.43$ & 0.280 & $-39.13 \pm 0.75$ \\
\hline
\end{tabular}




\section{DISCUSSION}

The results presented indicate the successful synthesis of amphiphilic copolymer via reductive amination and succinylation, respectively, onto the CS backbone. The copolymer was confirmed by ${ }^{1} \mathrm{H}$ NMR spectroscopy, FTIR, GPC and elemental analysis. These results revealed the successful functionalization of $N$-benzyl groups or N,O-succinyl groups onto the CS backbone. The formation polymeric micelles in aqueous solution occur when the concentration of the copolymer increases above CMC. The CMC of BSCS polymeric micelles was very low. This value indicates the polymeric micelles are stable of structure. The major requirements for drug delivery to the body are the polymers used for micelle preparation should be non-toxic. Here, the cytotoxicity of BSCS micelles was determined by quantitative evaluation of cell viability using Caco-2 cells. As reported the BSCS copolymer micelles had low cytotoxicity and would be safe in vivo.

One important problem in drug delivery is the deficient solubility of drugs. Polymeric micelles are one of the most promising carriers for drug delivery and have improved the solubility of poorly water soluble drugs by entrap the drug into hydrophobic core. Generally, the solubility of drugs depends on particle size, the nature and composition of the solvent medium, temperature, physical form of solid, nature of solute, etc [23]. In Table 2, MX and PRX are classified of enolic acid derivatives. They have two acid-base dissociation constants $\mathrm{pK}_{\mathrm{a}}(1.09,4.18$ for $\mathrm{MX}$ and $1.86,5.46$ for PRX). The isoelectric points (pl), which were computed from $\left(\mathrm{pK}_{\mathrm{a} 1}+\mathrm{pK}_{\mathrm{a} 2}\right) / 2$ of $\mathrm{MX}$ and PRX, are 2.63 and 3.66, respectively. The $\mathrm{pl}$ is defined as the $\mathrm{pH}$ at which the drugs have no net charge. When the $\mathrm{pH}<\mathrm{pl}$, drugs display a positive charge or become a cationic, but when $\mathrm{pH}>\mathrm{pl}$, drugs turn into a negative charge or become an anionic. KP and IND belong to propionic acid derivatives with $\mathrm{pK}_{\mathrm{a}} \approx 4.4$ and acetic acid derivatives with $\mathrm{pK}_{\mathrm{a}} \approx 4.5$, respectively. Both of them are negatively charged or anionic at $\mathrm{pH}>\mathrm{pK}_{\mathrm{a}}$ [22]. Thus, the solubility of NSAIDs (MX, PRX, KP and IND) increased with the increase in $\mathrm{pH}$ because of ionization of the drugs. However, these drugs present low solubility in aqueous solution (Table 2). The improvement in EE of the four model drugs through BSCS polymeric micelles can be ranked as $\mathrm{KP}(70.6 \%)>\operatorname{PRX}(50.2 \%)>\mathrm{MX}$ $(18.3 \%)>$ IND (10.3\%) (Figure 4a). In addition, the drug LC of these BSCS micelles for the four model drugs was in the similar rank order; $\mathrm{KP}$ $(282.9 \mu \mathrm{g} / \mathrm{mg})>$ PRX $(200.8 \mu \mathrm{g} / \mathrm{mg})>\operatorname{MX}(73.7$ $\mu \mathrm{g} / \mathrm{mg})>\operatorname{IND}(41.2 \mu \mathrm{g} / \mathrm{mg})$.
These high contents indicate successful encapsulation of poorly water soluble drug to polymeric micelles. The LC of polymeric micelles is influenced by several factors such as composition, molecular weight and structure of polymer and drug [24]. This result revealed that the chemical structure of drugs is the key factor to control EE and LC. It is thought that BSCS micellar encapsulation was occurred not only by hydrophobic interaction but also by the forces assembled via the attraction between benzyl groups in the copolymer and aromatic groups in drugs. These results were in agreement with previously studied encapsulation behaviors of anticancer drugs, octaethylporphine (OEP), meso-tetraphenyl porphine (mTPP) and camptothecin (CPT), in Pluronic and poly(ethyleneglycol)-distearoylphosphatidyl ethanolamine (PEG-DSPE) polymeric micelles. The results indicated that the high efficacy of drug loading depends on the type of polymer and drug used and their ratios. The phenyl groups in mTPP might lead to attraction between alkyl groups in the polymer and increase drug incorporation [25]. The particle sizes of the drugs encapsulated into polymeric micelles ranged from 312 to $433 \mathrm{~nm}$ and were larger than the blank polymeric micelles $(226.63 \mathrm{~nm})$ as a result of drug entrapment. The zeta potential of all micelles formation in deionized water $(\mathrm{pH} 5)$ exhibited negatively charge $(-38$ to $-41 \mathrm{mV})$ of carboxyl group in hydrophilic moieties resulting in the particles tended to poorly aggregate [26].

\section{CONCLUSION}

BSCS grafted copolymer has been successfully synthesized and prepared as polymeric micelles in aqueous solutions. NSAIDs (MX, PRX, KP and IND) have also been successfully incorporated in the hydrophobic inner core by evaporation method. Among the drug-loaded micelles, KPloaded BSCS polymeric micelles showed the highest loading capacity. Drug loading depends on the molecular structure of the drugs. Therefore, generation of BSCS polymeric micelle in this study represents an efficient and attractive approach for solubilization of NSAIDs.

\section{DECLARATIONS}

\section{Acknowledgement}

The authors would like to acknowledge the Commission of Higher Education (Thailand) and the Thailand Research Fund through the Golden Jubilee Ph.D. Program (grant no. PHD/0027/2556), Silpakorn University Research and Development Institute (SURDI 59/01/46), 
and National Nanotechnology

(NANOTEC), Thailand.

\section{Conflict of Interest}

No conflict of interest associated with this work.

\section{Contribution of Authors}

The authors declare that this work was done by the authors named in this article and all liabilities pertaining to claims relating to the content of this article will be borne by them.

\section{Open Access}

This is an Open Access article that uses a funding model which does not charge readers or their institutions for access and distributed under the terms of the Creative Commons Attribution License (http://creativecommons.org/licenses/by/ 4.0) and the Budapest Open Access Initiative (http://www.budapestopenaccessinitiative.org/rea d), which permit unrestricted use, distribution, and reproduction in any medium, provided the original work is properly credited.

\section{REFERENCES}

1. Aliabadi HM, Elhasi S, Mahmud A, Gulamhusein R, Mahdipoor $P$, Lavasanifar $A$. Encapsulation of hydrophobic drugs in polymeric micelles through cosolvent evaporation: The effect of solvent composition on micellar properties and drug loading. Int $J$ Pharm. 2007; 329: 158-165.

2. Lu Y, Park K. Polymeric micelles and alternative nanonized delivery vehicles for poorly soluble drugs. Int J Pharm. 2013; 453(1): 198-214.

3. Jatwani S, Rana AC, Singh G, Aggarwal G. An overview on solubility enhancement techniques for poorly soluble drugs and solid dispersion as an eminent strategic approach. Int J Pharm Sci Res. 2012; 3(4): 942-956.

4. G"okt"urk S, C,alıs, kan E, Talman RY, Var U, A study on solubilization of poorly soluble drugs by cyclodextrins and micelles: complexation and binding characteristics of sulfamethoxazole and trimethoprim. Sci World J. 2012. doi: 10.1100/2012/718791.

5. Adams ML, Lavasanifar A, Kwon GS. Amphiphilic block copolymers for drug delivery. J Pharm Sci. 2003; 92(7): 1343-1355.

6. Kedar U, Phutane P, Shidhaye S, Kadam V. Advances in polymeric micelles for drug delivery and tumor targetingreview article. Nanomed Nanotech Biol Med. 2010; 6: 714-729.

7. Riva $R$, Ragelle $H$, Rieux A, Duhem $N$, Je'ro'me $C$, Pre'at V. Chitosan and chitosan derivatives in drug delivery and tissue engineering. Adv Polym Sci. 2011; 244: 19-44.
8. Wu Y, Li M, Gao H. Polymeric micelle composed of PLA and chitosan as a drug carrier. J Polym Res. 2009; 16(1): 11-18.

9. Lia $W$, Peng $H$, Ning $F$, Yao L, Luo $M$, Zhao $Q$, Zhu $X$, Xiong $H$. Amphiphilic chitosan derivative-based coreshell micelles: Synthesis, characterisation and properties for sustained release of Vitamin D3. Food Chem. 2014; 152: 307-315.

10. Sun Y, Gu L, Gao Y. Preparation and characterization of 5-fluorouracil loaded chitosan microspheres by a twostep solidification method. Chem. Pharm. Bull. 2010; 58: 891-895.

11. Yuan ZT, Ye YJ, Gao F, Yuan H, Lan M, Lou K, Wang W. Chitosan-graft-b-cyclodextrin nanoparticles as a carrier for controlled drug release. Int. J. Pharm. 2013; 446: 191-198.

12. Sajomsang W, Gonil P, Saesoo S, Ruktanonchai UR, Srinuanchai $W$, Puttipipatkhachorn S. Synthesis and anticervical cancer activity of novel $\mathrm{pH}$ responsive micelles for oral curcumin delivery. Int $J$ Pharm. 2014; 477: 261-272.

13. Woraphatphadung T, Sajomsang W, Gonil P, Saesoo S, Opanasopit $P$. Synthesis and characterization of $\mathrm{pH}$ responsive $\mathrm{N}$-naphthyl-N,O-succinyl chitosan micelles for oral meloxicam delivery. Carbohydr Polym. 2015; 121: 99-106.

14. Woraphatphadung $T$, Sajomsang W, Gonil $P$, Treetong A, Akkaramongkolporn $P$, Ngawhirunpat $T$, Opanasopit $P$. pH-Responsive polymeric micelles based on amphiphilic chitosan derivatives: Effect of hydrophobic cores on oral meloxicam delivery. Int J Pharm. 2016; 497: 150-160.

15. Liu CG, Desai KG, Chen XG, Park HJ. Linolenic acidmodified chitosan for formation of self-assembled nanoparticles. J Agric Food Chem. 2005; 53: 437-441.

16. Mosmann T. Rapid colorimetric assay for cellular growth and survival: application to proliferation and cyto-toxicity assays. J Immunol Methods. 1983; 65: 55-63

17. Duangjit $S$, Opanasopit $P$, Rojanarata $T$, Ngawhirunpat $T$. Evaluation of meloxicam-loaded cationic transfersomes as transdermal drug delivery carriers. Am Assoc Pharm Sci Technol. 2013; 14(1): 133-140.

18. Madhukar A, Sudheer Kumar V, Anand P, Samrat CH, Hemlatha T, Tajuddin Baba M. Rapid analytical method development and validation of Piroxicam by RP-HPLC. J Chem Pharm Res. 2011; 3(3): 464-469.

19. Nov'akov' L, Matysov' L, Havl'ıkov' L, Solich $P$. Development and validation of HPLC method for determination of indomethacin and its two degradation products in topical gel. J Pharm Biomed Anal. 2005; 37: 899-905.

20. Sajomsang W, Tantayanon S, Tangpasuthadol V, Thatte $M$, Daly WH. Synthesis and characterization of $\mathrm{N}$-aryl chitosan derivatives. Int J Biol Macromol. 2008; 43: 7987.

21. Scott M. Intravenous indomethacin. Pharm J. 1980; 2: 614.

22. Samprasit $W$, Rojanarata $T$, Akkaramongkolporn $P$, Ngawhirunpat T, Opanasopit $P$. Reused cyclodextrin as

Trop J Pharm Res, October 2017; 16(10): 2356 
a new way to deliver and enhance drug loading onto ion exchange resin. Pharm Dev Technol. 2014. doi: 10.3109/10837450.2014.926920.

23. Deepshikha S, Vaibhav S, Anand KA, Chatterjee DP. Techniques for solubility enhancement of poorly soluble drugs: an overview. J Med Pharm Allied Sci. 2012; 01: 18-38.

24. Kabanov AV, Nazarova IR, Astafieva IV, Batrakova EV, Alakhov VY, Yaroslavov AA, Kabanov VA. Micelle formation and solubilization of fluorescent probes in poly(oxyethylene-b-oxypropylene-b-oxyethylene) solutions. Macromolecules. 1995; 28: 2303-2314.

25. Sezgin Z, Yüksel N, Baykara T. Preparation and characterization of polymeric micelles for solubilization of poorly soluble anticancer drugs. Eur $J$ Pharm Biopharm. 2006; 64(3): 261-268.

26. Shende PK, Gauda RS, Bakal R, Patil D. Effect of inclusion complexation of meloxicam with $\beta$-cyclodextrin and $\beta$-cyclodextrin-based nanosponges on solubility, in vitro release and stability studies. Colloid Surface $B$. 2015; 136: 105-110. 